Check for updates

Cite this: RSC Adv., 2017, 7, 43978

Received 2nd June 2017

Accepted 24th August 2017

DOI: 10.1039/c7ra06162e

rsc.li/rsc-advances

\title{
Novel benzimidazole-mediated phthalonitrile/ epoxy binary blends system with synergistic curing behavior and outstanding thermal properties $\uparrow$
}

\author{
Jianghuai Hu, Rui Sun, Yihao Wu, Jiangbo Lv, Zhiping Wang, Ke Zeng (D) * \\ and Gang Yang*
}

Binary blends composed of benzimidazole-containing phthalonitrile (PNBI) and epoxy resin E51 were prepared. The PNBI/E51 (PE) blends showed good compatibilities and unique synergistic curing behaviors on full consumption of nitrile groups (PE19, PNBI:E51 = 1: 9 in weight ratio) and epoxy groups in the view of DSC, rheology and IR. Curing procedures of the PE blends were determined by DSC and DMA. Studies on the curing procedure showed that the PE blends exhibited good processability and could be fully cured at a temperature lower than $210^{\circ} \mathrm{C}$. Studies on the cured PE blends showed that they have excellent thermal and mechanical properties. The glass transition temperatures $\left(T_{\mathrm{g}}\right)$ of cured PNBI/E51 blends were higher than $207^{\circ} \mathrm{C}$ (obtained by DMA). The $5 \%$ weight loss $\left(T_{5}\right)$ and char yield at $800{ }^{\circ} \mathrm{C}$ (CR) were higher than $360^{\circ} \mathrm{C}$ and $14 \%$ in nitrogen, respectively (obtained by TGA). Consequently, this study shows a novel modification in the method for the preparation of epoxy or phthalonitrile blend systems.

\section{Introduction}

Because of their excellent chemical and corrosion resistance, good dimensional stability, high modulus and tensile strength, epoxy resins have been widely used in various fields such as electronic industries, high-performance composites and aerospace applications. ${ }^{1,2}$ However, conventional epoxy resins still have numerous defects such as low thermal properties and low $T_{\mathrm{g}}$, which are unable to meet the requirements of advanced materials. Therefore, studies on improving thermal and mechanical performances of epoxy resins have become an important need. ${ }^{3,4}$ The approach to improve the thermal properties of epoxy resins could be divided into three categories: modifying skeletons of epoxy monomers or polymers, changing the curing agents and blending with other materials. ${ }^{2,4-6}$

Phthalonitrile resins have been studied for over 30 years as a class of high temperature/performance polymers. Because of their excellent thermal and thermal oxidative stabilities, outstanding mechanical properties, and superior flame resistance, phthalonitrile resins have been used in numerous fields, such as electronic packaging applications, marine applications, and aerospace applications. ${ }^{-9}$ However, high curing

State Key Laboratory of Polymer Materials Engineering, College of Polymer Science and Engineering, Sichuan University, Chengdu 610065, P. R. China.E-mail: zk_ican@sina. com; yanggang65420@163.com; Fax: +86-28-85462736; Tel: +86-28-85462736

$\dagger$ Electronic supplementary information (ESI) available. See DOI: 10.1039/c7ra06162e temperatures $\left(>300{ }^{\circ} \mathrm{C}\right)$ and long curing durations limit their widespread applications..$^{5,7-9}$

As discussed above, the study on the combination of the characteristics of these two types of resins will be a valuable research. ${ }^{5,10-13}$ Researchers have conducted various studies on this topic. Dominguez et al. reported a series of binary blends composed of phthalonitrile monomer and oligomer along with epoxy resin. The blends exhibited attractive combination of processability and high-temperature properties..$^{10}$ Liu et al. reported a 4-aminophenoxyphthalonitrile/epoxy resin blend system that exhibited an attractive self-promoted curing reaction, desirable processing features, excellent thermal and thermal oxidative stabilities, and high char yields. ${ }^{13}$ Although these reports have inspired us to study the blend systems of phthalonitrile and epoxy, there are a few problems to be solved. Most of the reported curing agents of phthalonitrile/epoxy resin blends were aromatic amines, which are well-known as an important class of curing agents for epoxy resins. However, a large number of amino groups was consumed in the lowtemperature curing stage. Thus, a low content of amino groups and low activity of curing agents are not sufficient to initiate the reaction of nitrile groups at low temperatures (lower than $200^{\circ} \mathrm{C}$ ). Therefore, the reaction of nitrile groups should be carried out at a higher temperature (usually higher than $300^{\circ} \mathrm{C}$ ). However, due to the relatively low thermal stability of epoxy resins, ${ }^{3,4}$ their curing reaction is usually carried out at temperatures below $200^{\circ} \mathrm{C}$. Thus, the reduction in curing temperatures of epoxy/phthalonitrile blend systems becomes a basic problem 
to be solved. The conversion of nitrile groups and the compatibility of the blends should also be taken into consideration.

In our previous study, a self-promoted benzimidazolecontaining phthalonitrile (PNBI) was synthesized. ${ }^{14,15}$ However, the curing reaction of PNBI is a high temperature and sluggish process, which may be induced by the weak basicity of benzimidazole group. ${ }^{16}$ Simultaneously, imidazoles are an important class of medium or high-temperature curing agents for epoxy resins. ${ }^{17-19}$ It is well-known that the curing reactions of epoxy monomers with imidazole groups are exothermic producing a large amount of active intermediates (e.g. benzimidazolium cation and oxygen anion). If the acidity and basicity are considered to be important factors in determining the activity of the curing agents of phthalonitrile, the active intermediates may have higher catalytic activities for phthalonitrile, which would reduce the curing temperature and speed up the curing rate. ${ }^{16-19}$ Thus, high activity curing agents, which derive from the reaction of epoxy monomer and benzimidazole, could initiate the curing reaction of phthalonitrile at low temperatures. As discussed above, the study on PNBI/epoxy binary system may be significant considering its thermal properties and the reactivity of phthalonitrile.

In this study, to explore new solutions for phthalonitrile/ epoxy blend systems, the novel PNBI/epoxy resin E51 (PE) binary blend systems were constructed. The PE binary blend systems exhibited a unique self-promoted synergistic curing behavior and showed good compatibility. The curing procedures of PE blends were determined by DSC and DMA. Studies on the curing procedure showed that the PE blends exhibited good processability and could be fully cured at a temperature lower than $210^{\circ} \mathrm{C}$. The systematic studies showed that the epoxy and phthalonitrile groups in the PE blend systems could be fully consumed at lower temperatures $\left(\leq 210{ }^{\circ} \mathrm{C}\right)$ during the curing process, and the cured PNBI/EP blend system showed good processability, homogeneous structure, outstanding thermal properties and high glass transition temperatures $\left(T_{\mathrm{g}}\right)$.

\section{Experimental}

\subsection{Materials}

Low molecular weight bisphenol A liquid epoxy resin YN1828LA (E51, epoxy equivalent: 186-189 $\mathrm{g} \mathrm{mol}^{-1}$ ) was bought from Jiangsu Yangnong Chemical Group Co., Ltd. Furthermore, 4-nitrophthalonitrile was purchased from Ji'nan Weido
Chemical Co. Ltd. and recrystallized from ethanol. Dimethyl sulfoxide (DMSO), dicyclohexylcarbodiimide (DCC), potassium carbonate and tetrahydrofuran (THF) were purchased from Tianjin BoDi Co. Ltd. o-Phenylenediamine, 4-hydroxybenzoic acid and other chemicals were purchased from Chengdu Kelong Chemical Reagent Co. Ltd. and used as received.

\subsection{Synthesis of 4-(4-(1H-benzo[d]imidazol-2-yl)phenoxy) phthalonitrile (PNBI)}

PNBI was synthesized according to reported literature..$^{14,15}$

\subsection{Preparation of the PNBI/E51 blends}

The PNBI/E51 blend (Scheme 1) was prepared by mixing a mass ratio of $1: 9$ with PE19 and $2: 8$ with PE28 in a flask. The mixture was stirred until it became homogeneous.

\subsection{Preparation of the PNBI/E51 blend resins}

Each PNBI/E51 blend (PE19 and PE28) was added into a singleneck bottle and heated at $95-100{ }^{\circ} \mathrm{C}$ until the mixture became a transparent brown solution (Scheme 1 and Fig. $\mathrm{S} 1 \dagger$ (the mixture exhibited good storage stability)). After defoaming in vacuum for $10 \mathrm{~min}$, the solution was poured into a hot mold $\left(100{ }^{\circ} \mathrm{C}\right)$ and treated using a heating program in an oven under a nitrogen atmosphere.

Heating program:

PE19: $100{ }^{\circ} \mathrm{C} / 0.5 \mathrm{~h}, 130{ }^{\circ} \mathrm{C} / 1 \mathrm{~h}, 150{ }^{\circ} \mathrm{C} / 2 \mathrm{~h}, 180{ }^{\circ} \mathrm{C} / 2 \mathrm{~h}$, $210{ }^{\circ} \mathrm{C} / 2 \mathrm{~h}$.

PE28: $100{ }^{\circ} \mathrm{C} / 0.5 \mathrm{~h}, 130{ }^{\circ} \mathrm{C} / 1 \mathrm{~h}, 150{ }^{\circ} \mathrm{C} / 2 \mathrm{~h}, 180{ }^{\circ} \mathrm{C} / 2 \mathrm{~h}$.

The abbreviation of cured products:

PE19-150: $100{ }^{\circ} \mathrm{C} / 30 \mathrm{~min}$ and $130{ }^{\circ} \mathrm{C} / 1 \mathrm{~h}$ and $150{ }^{\circ} \mathrm{C} / 2 \mathrm{~h}$, PE19-180: $100{ }^{\circ} \mathrm{C} / 30 \mathrm{~min}$ and $130{ }^{\circ} \mathrm{C} / 1 \mathrm{~h}$ and $150{ }^{\circ} \mathrm{C} / 2 \mathrm{~h}$ and $180{ }^{\circ} \mathrm{C} / 2 \mathrm{~h}$,

PE19-210: $100{ }^{\circ} \mathrm{C} / 30 \mathrm{~min}$ and $130{ }^{\circ} \mathrm{C} / 1 \mathrm{~h}$ and $150{ }^{\circ} \mathrm{C} / 2 \mathrm{~h}$ and $180{ }^{\circ} \mathrm{C} / 2 \mathrm{~h}$ and $210^{\circ} \mathrm{C} / 2 \mathrm{~h}$,

PE28-150: $100{ }^{\circ} \mathrm{C} / 30 \mathrm{~min}$ and $130{ }^{\circ} \mathrm{C} / 1 \mathrm{~h}$ and $150{ }^{\circ} \mathrm{C} / 2 \mathrm{~h}$, PE28-180: $100{ }^{\circ} \mathrm{C} / 30 \mathrm{~min}$ and $130{ }^{\circ} \mathrm{C} / 1 \mathrm{~h}$ and $150{ }^{\circ} \mathrm{C} / 2 \mathrm{~h}$ and $180{ }^{\circ} \mathrm{C} / 2 \mathrm{~h}$,

PE28-210: $100{ }^{\circ} \mathrm{C} / 30 \mathrm{~min}$ and $130{ }^{\circ} \mathrm{C} / 1 \mathrm{~h}$ and $150{ }^{\circ} \mathrm{C} / 2 \mathrm{~h}$ and $180{ }^{\circ} \mathrm{C} / 2 \mathrm{~h}$ and $210{ }^{\circ} \mathrm{C} / 2 \mathrm{~h}$,

PE28-250: $100{ }^{\circ} \mathrm{C} / 30 \mathrm{~min}$ and $130{ }^{\circ} \mathrm{C} / 1 \mathrm{~h}$ and $150{ }^{\circ} \mathrm{C} / 2 \mathrm{~h}$ and $180{ }^{\circ} \mathrm{C} / 2 \mathrm{~h}$ and $210^{\circ} \mathrm{C} / 2 \mathrm{~h}$ and $250{ }^{\circ} \mathrm{C} / 2 \mathrm{~h}$,

PE28-300: $100{ }^{\circ} \mathrm{C} / 30 \mathrm{~min}$ and $130{ }^{\circ} \mathrm{C} / 1 \mathrm{~h}$ and $150{ }^{\circ} \mathrm{C} / 2 \mathrm{~h}$ and $180{ }^{\circ} \mathrm{C} / 2 \mathrm{~h}$ and $210{ }^{\circ} \mathrm{C} / 2 \mathrm{~h}$ and $250{ }^{\circ} \mathrm{C} / 2 \mathrm{~h}$ and $280{ }^{\circ} \mathrm{C} / 1 \mathrm{~h}$.
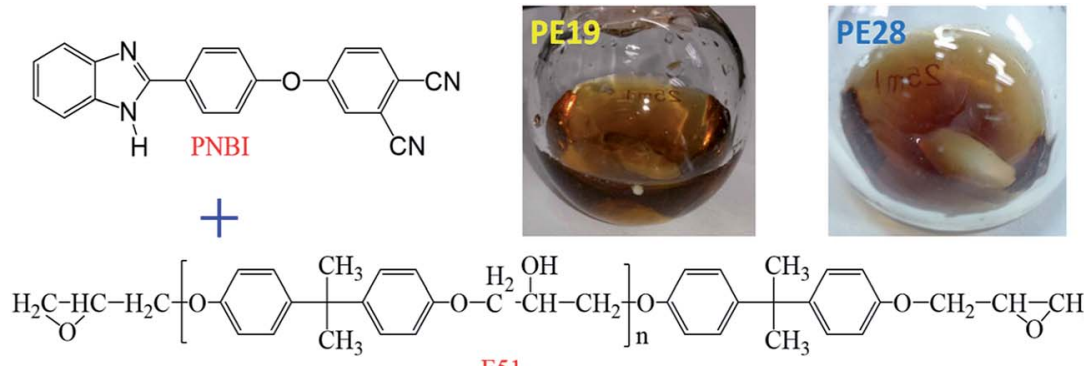

E51

Scheme 1 The chemical structures of PNBI and E51 and the photographs of PE19 and PE28. 


\subsection{Measurements}

${ }^{1} \mathrm{H}$ NMR (300 MHz) spectra were obtained with a Bruker Avance300 NMR spectrometer, using DMSO- $d_{6}$ as the solvent and tetramethylsilane (TMS) as the internal standard. FTIR spectra were obtained with a Nicolet FTIR-380 Fourier transform infrared spectrometer using $\mathrm{KBr}$ pellets. Thermogravimetric analysis (TGA) was carried out in the temperature range from $40{ }^{\circ} \mathrm{C}$ to $800{ }^{\circ} \mathrm{C}$ using a TA instrument Q500 thermogravimetric analyzer in nitrogen or air $\left(60 \mathrm{~mL} \mathrm{m^{-1 }}\right)$ at a heating rate of $10{ }^{\circ} \mathrm{C} \mathrm{min}^{-1}$. Differential scanning calorimetry (DSC) was carried out using a TA Instrument Q200 Differential Scanning Calorimeter using nitrogen as the purge gas. Conventional DSC measurements were performed at a heating rate of $2{ }^{\circ} \mathrm{C} \mathrm{min}^{-1}$, $5{ }^{\circ} \mathrm{C} \min ^{-1}, 10{ }^{\circ} \mathrm{C} \min ^{-1}$, and $15{ }^{\circ} \mathrm{C} \min ^{-1}$. The rheological behaviors of the powder mixture of the PNBI/E51 blends were studied in dynamic oscillation mode using a TA Instruments AR-2000ex rheometer with a $25 \mathrm{~mm}$ diameter parallel plate in conjunction with an environmental testing chamber for temperature control. The tests were performed at a low strain value $\left(2.5 \times 10^{-4}\right)$ and a frequency of $1 \mathrm{~Hz}$. The samples were prepared by press-molding the powder mixture (approximately $0.45 \mathrm{~g}$ ) at room temperature. The compacted sample disk was subsequently loaded into the rheometer fixture. The dynamic storage modulus of the mixture was also monitored at 100, 130 and $150{ }^{\circ} \mathrm{C}$ in air as a function of time, with a temperature ramp to acquire values at a rapid heating rate of $50{ }^{\circ} \mathrm{C} \mathrm{min}^{-1}$, and equilibrated for $1 \mathrm{~min}$. Dynamic mechanical analysis (DMA) was recorded on a TA instrument DMA Q800 at a heating rate of $5{ }^{\circ} \mathrm{C} \min ^{-1}$ with a load frequency of $1 \mathrm{~Hz}$ in air (specifications of blends: $2.5 \mathrm{~mm}$ thick, $12 \mathrm{~mm}$ wide and $30 \mathrm{~mm}$ long). The morphologies of PNBI/E51 were determined by a JEOL JSM$7500 \mathrm{~F}$ field-emission scanning electron microscopy (SEM) system. The specimens were coated with $\mathrm{Au}$ prior to observation. For water uptake, samples of the cured resins were immersed in boiling distilled water at $96{ }^{\circ} \mathrm{C}$ for 45 hours. Then, the samples were removed from the boiling water, dried with filter paper, and weighed periodically to determine the amount of water absorbed.

\section{Results and discussion}

\subsection{Curing behaviors}

The TGA curves of PNBI, E51 and their blends (PE19 and PE28) are shown in Fig. 1. As shown in Fig. 1, the temperature at 1\% weight loss $\left(T_{1}\right), 5 \%$ weight loss $\left(T_{5}\right)$, and at $10 \%$ weight loss $\left(T_{10}\right)$ are 211,245 and $259{ }^{\circ} \mathrm{C}$, respectively, indicating that the curing temperature of phthalonitrile should be limited to $210{ }^{\circ} \mathrm{C}$. The thermal stabilities $\left(T_{5}, T_{10}\right.$ and $\mathrm{CR}$ at $\left.800^{\circ} \mathrm{C}\right)$ of E51 significantly improved when a small amount PNBI was added. The thermal properties of E51 improved with the increase in content of PNBI. Furthermore, the $T_{5}, T_{10}$, and CR of PE28 improved by $110{ }^{\circ} \mathrm{C}, 116{ }^{\circ} \mathrm{C}$, and $15 \%$, respectively, compared with those of pure E51. TGA studies indicate that PNBI could promote the curing reaction and increase the thermal stability of E51 (see ESI Fig. S2 $\dagger$ ). In order to further study the interactions and reactions between PNBI and E51, the DSC, rheology

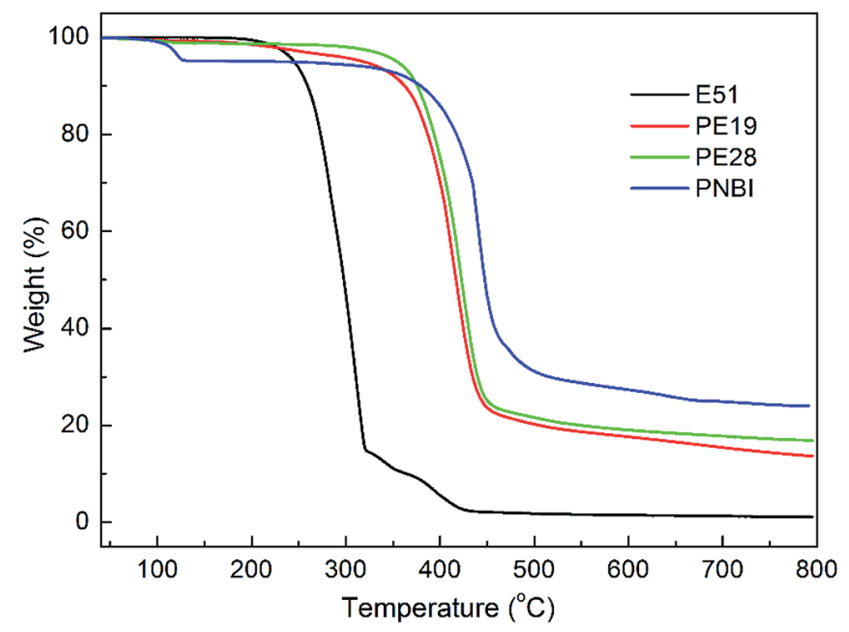

Fig. 1 The TGA curves of PNBI, E51, PE19 and PE28.

and IR analyses were carried out to study the curing behaviors of PE19 and P28.

The curing and rheological behaviors of PNBI, E51, PE19 and PE28 were studied using DSC and rheology techniques, as shown in Fig. 2 and 3, respectively. As found from Fig. 2, the melt peaks of PNBI could not be observed in the PNBI/E51 blends (PE19 and PE28), suggesting the good compatibility between PNBI and E51. Both PNBI/E51 blends exhibit three exothermic peaks around $140{ }^{\circ} \mathrm{C}$ (peak 1), $150{ }^{\circ} \mathrm{C}$ (peak 2) and above $180{ }^{\circ} \mathrm{C}$ (peak 3), which may be induced due to the polymerization of epoxy and phthalonitrile groups. All of the peaks shift to lower temperatures with increasing PNBI content, indicating that PNBI can efficiently promote the curing reaction of the PNBI/epoxy blends.

In order to further study the curing behaviors of the blends, a rheology measurement was carried out. As shown in Fig. 3, the viscosities of PE28 and PE19 increase rapidly when temperature is higher than 150 and $175{ }^{\circ} \mathrm{C}$, respectively. This further confirms the occurrence of the curing reactions. The curing temperatures decrease with PNBI contents, confirming that

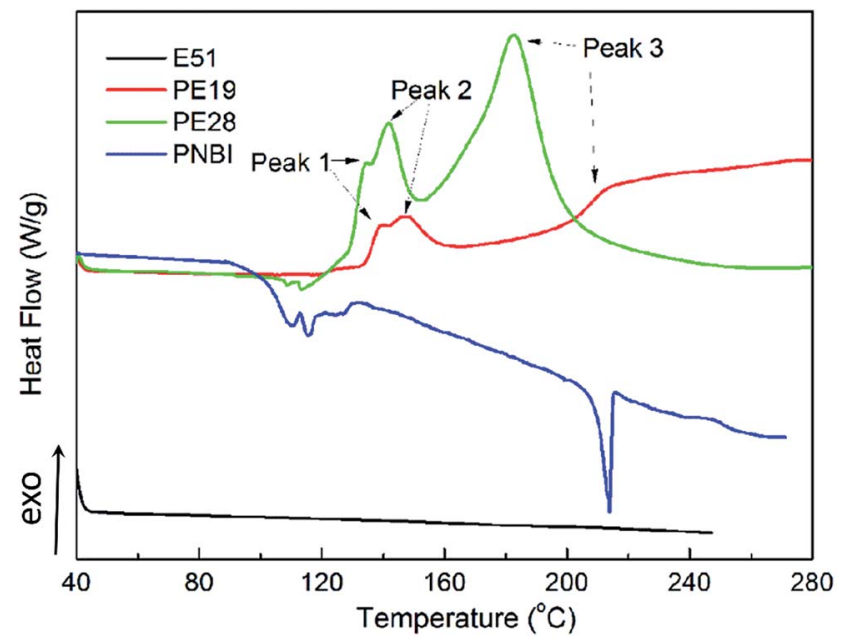

Fig. 2 The DSC curves of E51, PNBI and their blends. 


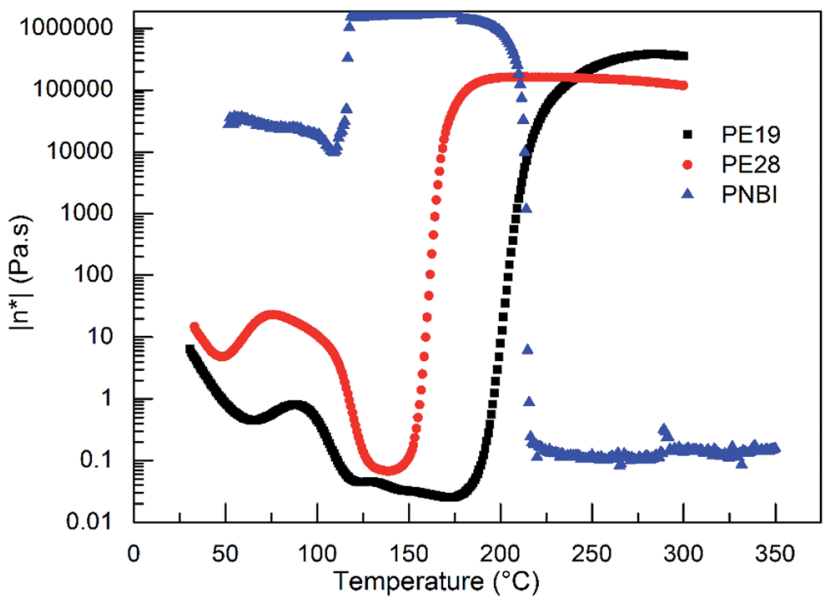

Fig. 3 The viscosity curves of PNBI, PE19 and PE28 obtained by rheology.

PNBI could promote the curing reaction of the PNBI/epoxy blends. However, the reactive groups involved in the reaction are still uncertain. Therefore, the products obtained after the rheology tests were used to study their structures using IR analysis. The IR spectra of PE28 and the products obtained after the rheology tests carried out up to $300{ }^{\circ} \mathrm{C}$ (PE19 R and PE28 R) are presented in Fig. 4. As shown in Fig. 4, both of the peaks of nitrile (around $\left.2230 \mathrm{~cm}^{-1}\right)$ and epoxy group $\left(915 \mathrm{~cm}^{-1}\right)$ disappear in PE19 R and PE28 R. Moreover, the characteristic peaks around $1630 \mathrm{~cm}^{-1}$ are observed in PE19 R and PE28 R, which correspond to the formation of isoindoline. The complete consumption of nitrile group, which may be induced by the formation of isoindoline other than triazine ring, was rarely reported before. ${ }^{14,16,20,21}$ The complete consumption of nitrile group inspired us to study the preparation and the properties of PNBI/epoxy resins. In addition, whether the entire curing process can be controlled within $210^{\circ} \mathrm{C}$ is a challenge worthy of study. Thus, the determination of curing procedures and the

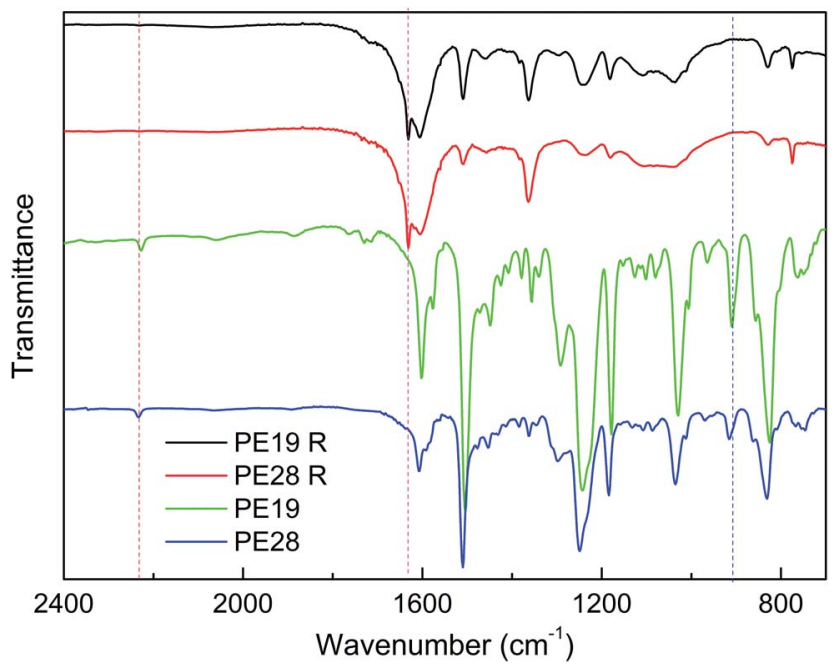

Fig. 4 The IR spectra of PE19, PE28 and their cured products (PE19 R and PE28 R) obtained after the rheology tests. studies on the cured resins are presented in the following section.

\subsection{Determination of curing procedures}

Curing temperature and curing time are key parameters, which affect the properties of the cured products. Thus, initially, DSC was introduced to determine the curing temperatures of PE19 and PE28. The DSC curves at different heating rates $(2,5,10$, and $\left.15{ }^{\circ} \mathrm{C} \mathrm{min}^{-1}, \beta\right)$ of PE19 and PE28 are shown in Fig. 5a and b, respectively. From Fig. 5 a and b, it can be clearly observed that the initial and the exothermic peak temperatures increase with the increase in heating rate. The initial curing temperatures $\left(T_{\mathrm{i}}\right)$ and the exothermic peak temperatures (peak 2, $T_{\mathrm{p}}$ ) at different heating rates of PE19 and PE28 were determined and plotted in Fig. $5 \mathrm{c}$. The plots of $T-\beta$ in Fig. $5 \mathrm{c}$ were used to calculate the initial curing temperatures and the curing exothermic peak temperatures at $\beta=0{ }^{\circ} \mathrm{C} \mathrm{min}{ }^{-1}$ using linear fitting method. ${ }^{22}$ The $T_{\mathrm{i}}$ and $T_{\mathrm{p}}$ of PE19 and PE28 at $\beta=$ $0{ }^{\circ} \mathrm{C} \min ^{-1}$ are obtained from Fig. $5 \mathrm{c}$, which are $102.4{ }^{\circ} \mathrm{C}$ $\left(\mathrm{PE} 19 T_{\mathrm{i}}\right), 127.2{ }^{\circ} \mathrm{C}\left(\mathrm{PE} 19 T_{\mathrm{p}}\right), 95.3{ }^{\circ} \mathrm{C}\left(\mathrm{PE} 28 T_{\mathrm{i}}\right)$ and $115.1{ }^{\circ} \mathrm{C}$ (PE28 $T_{\mathrm{p}}$ ). Based on the $T_{\mathrm{i}}$ and $T_{\mathrm{p}}$ obtained from Fig. $5 \mathrm{c}, 100{ }^{\circ} \mathrm{C}$ and $130^{\circ} \mathrm{C}$ were preliminarily determined as the temperatures for the pre-polymerization stages. In order to further confirm the feasibility of these two pre-polymerization temperatures, the isothermal rheological measurements were applied to study the curing behaviors of the PNBI/E51 blends at 100 and $130{ }^{\circ} \mathrm{C}$ (Fig. 5d). From the plots in Fig. 5d, it is evident that the low melt viscosities of PE19 and PE28 could be kept for $125 \mathrm{~min}$ and $60 \mathrm{~min}$, respectively, at $100{ }^{\circ} \mathrm{C}$, which indicate the outstanding processability of the PE blends at this temperature. Simultaneously, the melt viscosity of PE19 increases rapidly after 25 min dwell-time at $130{ }^{\circ} \mathrm{C}$, indicating its high activity at $130{ }^{\circ} \mathrm{C}$. Thus, using 100 and $130{ }^{\circ} \mathrm{C}$ as the pre-polymerization temperatures is feasible. According to the rheological curves in Fig. 5d, the pre-polymerization procedures are divided into two isothermal steps: isothermal process at $100{ }^{\circ} \mathrm{C}$ for $30 \mathrm{~min}$, and then an isothermal process at $130{ }^{\circ} \mathrm{C}$ for $1 \mathrm{~h}$.

According to the temperature-viscosity curves of the $\mathrm{PE}$ blends in Fig. 3, we conclude that the PE blend can be cured at around $200{ }^{\circ} \mathrm{C}$. Moreover, if the stability of epoxy groups is also considered, curing temperatures of the PE blends should be limited to the maximum temperature at $210{ }^{\circ} \mathrm{C}$. Therefore, the subsequent curing temperatures are preliminarily determined as 150,180 and $210{ }^{\circ} \mathrm{C}$. In order to further determine the isothermal time for each curing temperature, DSC and DMA were applied to monitor the change in the glass transition temperatures of the PE blends. The studies on isothermal time for each temperature point will be presented for PE19 as an example. The pre-polymers of PE19, obtained by curing at $100^{\circ} \mathrm{C}$ for $30 \mathrm{~min}$ and $130^{\circ} \mathrm{C}$ for $1 \mathrm{~h}$, were cured at $150{ }^{\circ} \mathrm{C}$ for 1 , 2 and 3 hours, and the corresponding $T_{\mathrm{g}}$ (obtained by DSC, see ESI Fig. S3 $\dagger$ ) at each curing time was 76, 98 and $101{ }^{\circ} \mathrm{C}$, respectively (Fig. 6). Considering that the $T_{\mathrm{g}}$ values are close to each other when the curing time is $2 \mathrm{~h}$ and $3 \mathrm{~h}, 2 \mathrm{~h}$ was determined as the curing time of PE19 at $150{ }^{\circ} \mathrm{C}$. Likewise, the sample of $150{ }^{\circ} \mathrm{C} / 2 \mathrm{~h}$ was applied to determine the curing time 

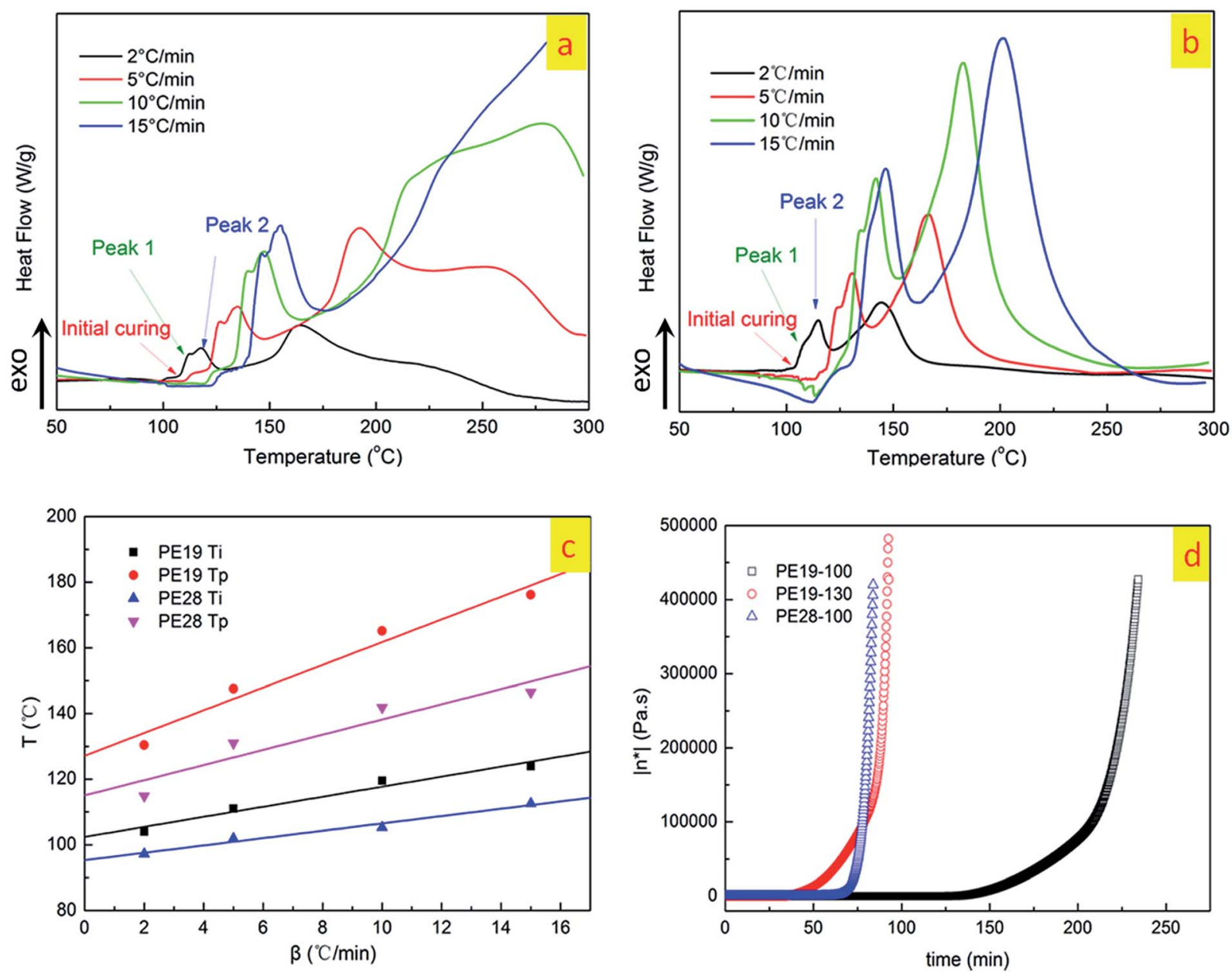

Fig. 5 The DSC curves of PE19 (a) and PE28 (b) at different heating rates, the relationships of initial and peak temperatures and $\beta$ (c), and isothermal rheology curves of PE19 and PE28 (d).

at $180^{\circ} \mathrm{C}$, and $2 \mathrm{~h}$ was determined as the curing time of PE19 at $180^{\circ} \mathrm{C}$ (obtained by DSC, see Fig. 6 and ESI Fig. S4†). The prepolymers of PE19, obtained by curing at $100{ }^{\circ} \mathrm{C}$ for $30 \mathrm{~min}$

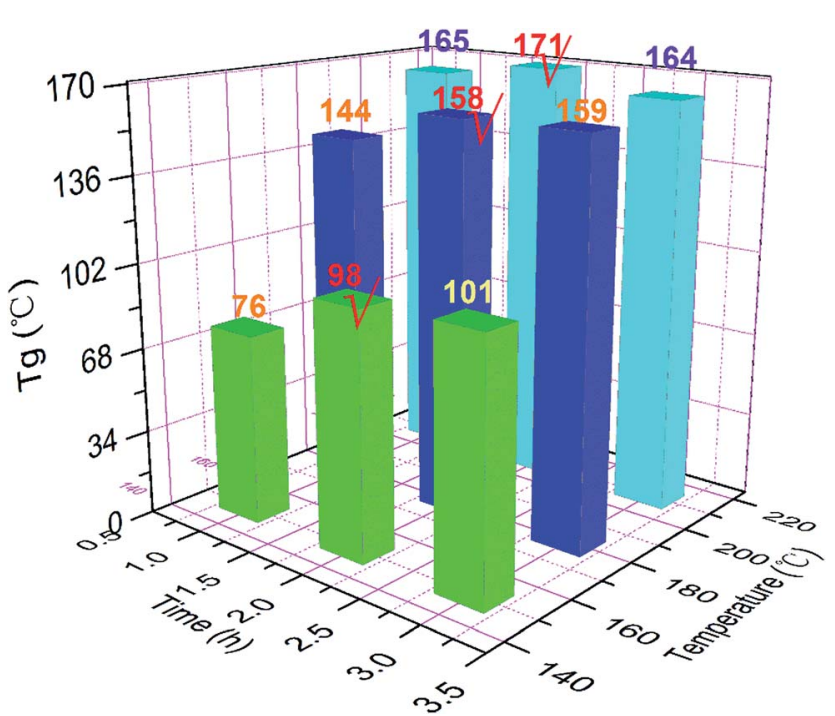

Fig. 6 The $T_{\mathrm{g}}$ of PE19 at different curing temperatures and curing times (obtained by DSC). and $1300^{\circ} \mathrm{C}$ for $1 \mathrm{~h}$ along with those obtained at $150{ }^{\circ} \mathrm{C}$ for $2 \mathrm{~h}$ and $180^{\circ} \mathrm{C}$ for $2 \mathrm{~h}$, were cured at $210^{\circ} \mathrm{C}$ for 1,2 and 3 hours and the $T_{\mathrm{g}}$ at each curing time was recorded as 165,171 and $164{ }^{\circ} \mathrm{C}$, respectively (obtained by DSC, see Fig. 6 and ESI Fig. S5 $†$ ). The variation of $T_{\mathrm{g}}$ for different curing times at $210^{\circ} \mathrm{C}$ indicates that the curing reaction and the degradation reaction may occur at the same time. This phenomenon further confirms that the curing temperatures of epoxy resins should be limited to the maximum temperature of about $210^{\circ} \mathrm{C}$. Therefore, $210{ }^{\circ} \mathrm{C}$ was determined as the final curing temperature for the curing reaction, and $2 \mathrm{~h}$ was selected as the curing time at $210^{\circ} \mathrm{C}$. The determination of curing procedure for PE28 is similar to that for PE19. However, because of the fact that $T_{\mathrm{g}}$ of PE28-180, cured at $210{ }^{\circ} \mathrm{C}$, was lower than that of PE28-180 cured at $180{ }^{\circ} \mathrm{C}$ (obtained by DMA, see Fig. 7), $180^{\circ} \mathrm{C}$ was determined as the final temperature of the curing reaction, and $2 \mathrm{~h}$ was determined as the curing time at $180{ }^{\circ} \mathrm{C}$. As discussed above, the curing procedures of PE19 and PE28 were determined as follows: 100 ${ }^{\circ} \mathrm{C} / 0.5 \mathrm{~h}, 130{ }^{\circ} \mathrm{C} / 1 \mathrm{~h}, 150{ }^{\circ} \mathrm{C} / 2 \mathrm{~h}, 180{ }^{\circ} \mathrm{C} / 2 \mathrm{~h}$, and $210{ }^{\circ} \mathrm{C} / 2 \mathrm{~h}$ and $100{ }^{\circ} \mathrm{C} / 0.5 \mathrm{~h}, 130^{\circ} \mathrm{C} / 1 \mathrm{~h}, 150^{\circ} \mathrm{C} / 2 \mathrm{~h}$, and $180^{\circ} \mathrm{C} / 2 \mathrm{~h}$, respectively.

The cured PE blends (PE19-210 and PE28-180) used for the structure and property characterizations were obtained by the curing procedures determined above. 


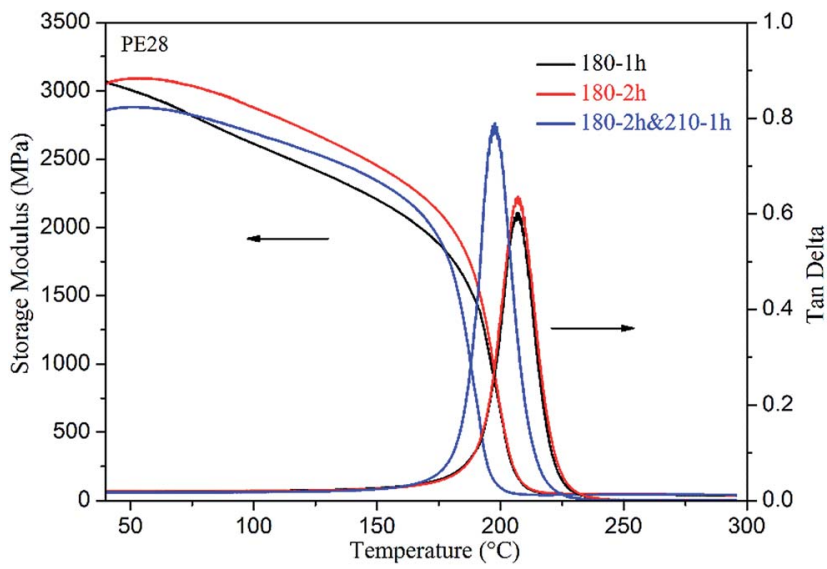

Fig. 7 The DMA curves of PE28 at different curing procedures (obtained by DMA).

\subsection{Structures and morphologies of cured resins}

The FTIR spectra of PE19 and PE28 of each curing stage are shown in Fig. 8a and b. As shown in Fig. 8a, the nitrile peak around $2230 \mathrm{~cm}^{-1}$ of PE19 could be observed when the blends were heated at $150{ }^{\circ} \mathrm{C}$ (PE19-150). To the best of our knowledge, this is a very low temperature in the view of the reaction of nitrile groups in the resin systems, and the full consumption of nitrile groups in phthalonitriles is also rarely reported., ${ }^{\mathbf{5 1 0 - 1 4 , 2 0 , 2 1}}$ This unique phenomenon indicates that few new high activity curing agents (e.g. oxygen anion) for phthalonitriles were generated during the curing reaction between epoxy monomer and benzimidazole. Moreover, the peak attributed to epoxy group $\left(915 \mathrm{~cm}^{-1}\right)$ disappeared in the spectra of cured PE blends, and a characteristic peak around $1630 \mathrm{~cm}^{-1}$ was observed, which corresponded to the formation of isoindoline. ${ }^{16,20,21}$ These results are consistent with the rheology studies (Fig. 3 and 4). Significantly, the nitrile peak is still evident in PE28-180, which indicates that the nitrile groups did not participate in the curing reaction on a large scale at a temperature below $180^{\circ} \mathrm{C}$. This phenomenon may be induced by the faster curing rates and the higher crosslinking density (higher $T_{\mathrm{g}}$ ), which inhibited the further reaction of nitrile groups (the DSC curves in ESI Fig. S2-S6 $†$ further confirm this speculation. The $T_{\mathrm{g}}$ of PE28 of each curing stage is higher than the corresponding curing temperature, indicating that the curing reaction at $150{ }^{\circ} \mathrm{C}$ and $180^{\circ} \mathrm{C}$ may occur at glass transition state. To further confirm this speculation, PE28-180 was cured at temperatures higher than the $T_{\mathrm{g}}$ of PE28-180 $\left(210{ }^{\circ} \mathrm{C}, 250{ }^{\circ} \mathrm{C}\right.$ and $\left.300{ }^{\circ} \mathrm{C}\right)$. The obtained IR spectra are shown in Fig. 8b (PE28-210, PE28-250 and PE28-300). As shown in Fig. 8b, the peaks of nitrile groups began to weaken when the samples were cured at $250{ }^{\circ} \mathrm{C}$. However, the peaks of nitrile groups did not completely disappear when the samples were cured at $300^{\circ} \mathrm{C}$, which may be due to the limited molecular motion. Despite the relatively high reactive temperatures of nitrile groups in PE28 (compared with PE19), the nitrile groups in PE28 possessed higher activities compared with those in pure PNBI ${ }^{14,15}$ which further confirmed that some high activity curing agents for phthalonitriles were
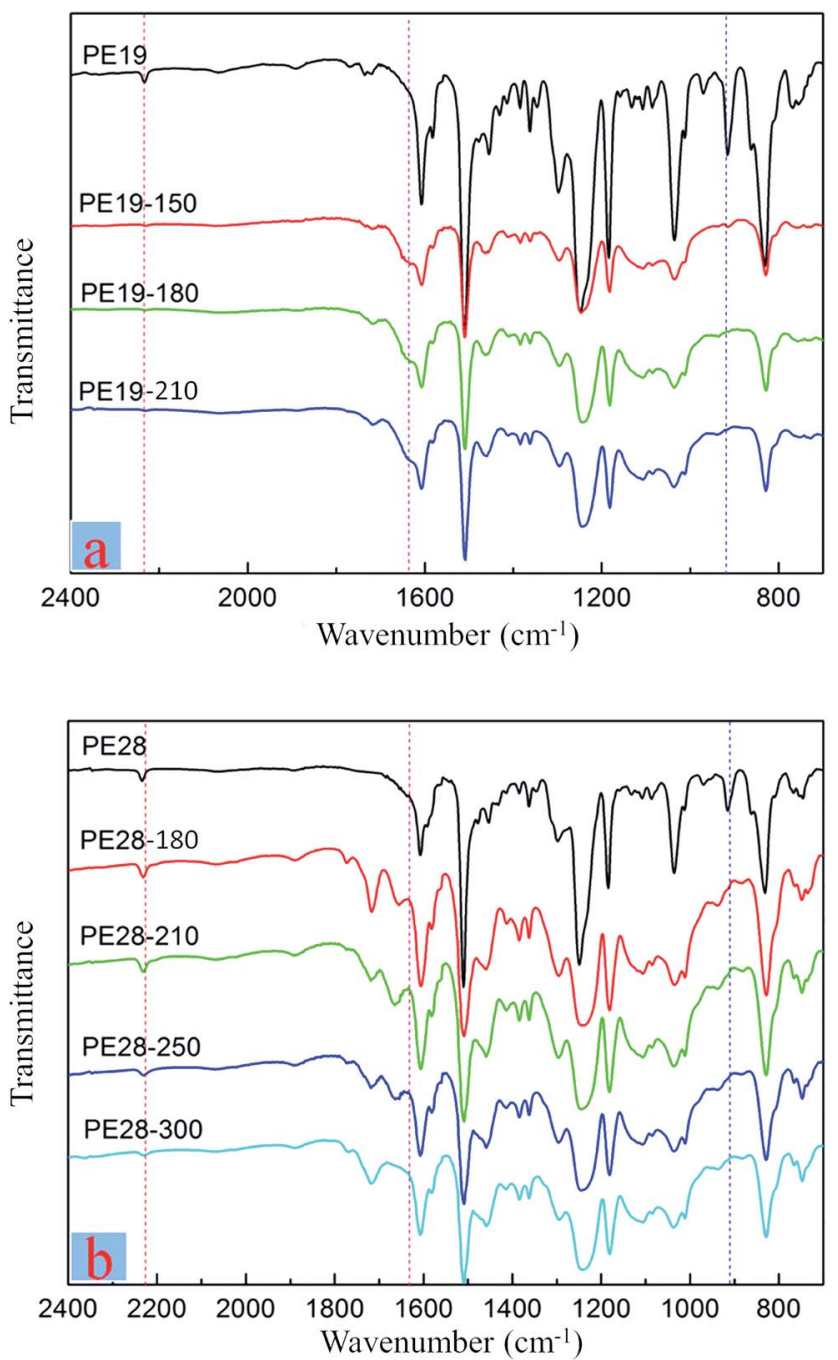

Fig. 8 The IR spectra of PE19 (a) and PE28 (b) at different curing stages.

generated during the curing reaction between the epoxy monomer and benzimidazole.

As discussed above, we believe that a synergistic curing between PNBI and epoxy resin occurred as follows: PNBI promoted the curing reaction of epoxy, and the products of the curing reaction of the epoxy monomer promoted the curing reaction of phthalonitrile. Based on the theory available and comparing with our obtained data, ${ }^{16,19}$ a synergistic curing mechanism between PNBI and epoxy group is proposed and presented in Scheme 2. Through the synergistic curing mechanism proposed, it is observed that the curing reaction of epoxy was initiated by benzimidazole, and then the products of epoxy ring opening (e.g. oxygen anion) further promoted the curing reaction of epoxy. Meanwhile, the active groups released by the reaction promoted the curing reaction of phthalonitrile. Due to the insoluble and infusible nature of thermoset resins, the study on curing mechanism of PNBI/epoxy resins is still a challenge. However, this study shows a novel modification in the method for the preparation of epoxy or phthalonitrile blend systems. 


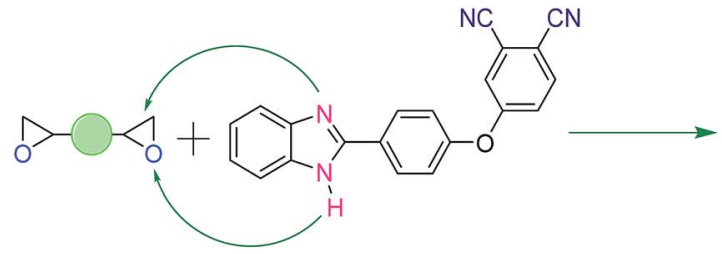<smiles>COc1ccc(C#N)c(C#N)c1</smiles>

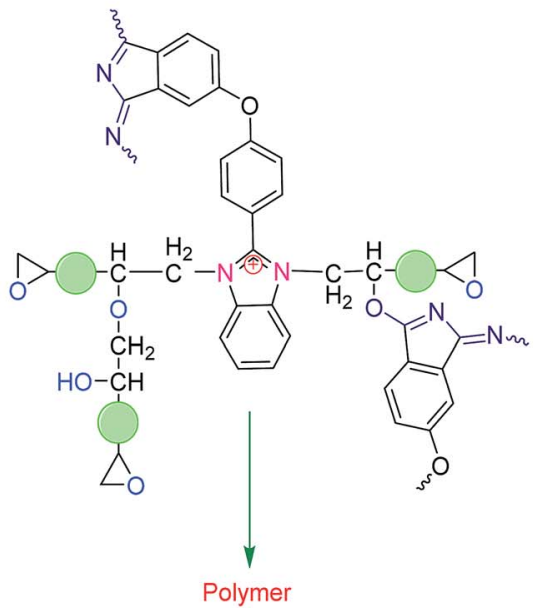<smiles>COc1ccc(C#N)c(C#N)c1</smiles><smiles>COc1ccc2c(c1)C(=N)N=C2OCC(CC1CO1)N(CC1CO1)c1c(-c2ccc(C)cc2)n(CC2CC2)c2ccccc12</smiles>

Scheme 2 Proposed synergistic curing mechanism between PNBI and epoxy.

The cross-sectional morphologies of the cured PE19 (Fig. 9a and b) and PE28 (Fig. 9c and d) are shown in Fig. 9. No significant phase separation could be observed, which indicates the good compatibility between PNBI and E51. In addition, no voids are observed in the cured PE blends at different magnifications, which confirms the void-free structures of the cured PE blends. The void-free structures indicate that no evident decomposition

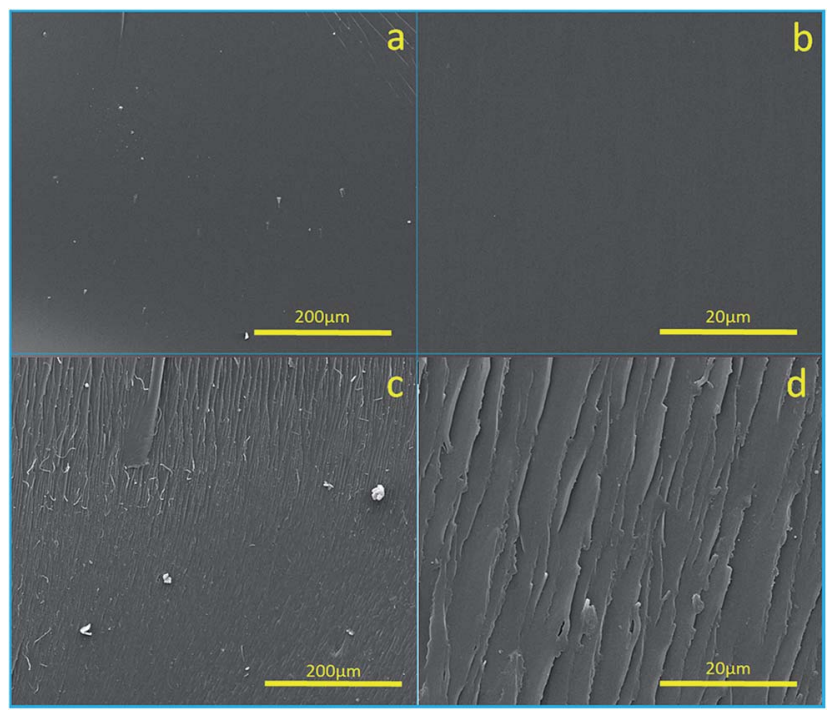

Fig. 9 SEM images of cured PE19 ( $a$ and b) and PE28 (c and d). occurred during the curing processes and also guarantee the excellent thermal and mechanical properties. As shown in Fig. 9c and d, the cross-section of the cured PE28 comprises long fracture lines, while the cured PE19 exhibits a smooth and featureless fractured cross-section. This observation indicates that the epoxy resin could be toughened using $\mathrm{PNBI}^{13,23}$ and this phenomenon may be correlated with the un-reacted nitrile groups.

\subsection{Thermal and mechanical properties}

The thermal and mechanical properties of the cured PE blends are shown in Fig. 10, 11 and Table 1. The TGA curves of PE19210 and PE28-180 in nitrogen and air atmosphere are shown in Fig. 11, and the specific parameters are tabulated in Table 1. The cured PE19 and PE28 exhibit good thermal properties with 14.2 and $17.7 \% \mathrm{CR}$ at $800{ }^{\circ} \mathrm{C}$ in nitrogen atmosphere, respectively. They show a weighted residual at $T_{5}$ at $369^{\circ} \mathrm{C}$ and $360{ }^{\circ} \mathrm{C}$ in nitrogen atmosphere and at $347{ }^{\circ} \mathrm{C}$ and $352{ }^{\circ} \mathrm{C}$ in air atmosphere. CR could be used as a criterion for evaluating the limiting oxygen index (LOI) by Van Krevelen and Hoftyzer equation below. ${ }^{22,24}$

$$
\mathrm{LOI}=17.5+0.4 \mathrm{CR}
$$

The LOI values of the cured PE19 and PE28 are 23.2 and 24.6, respectively. On the basis of LOI values, the cured PE19 and 


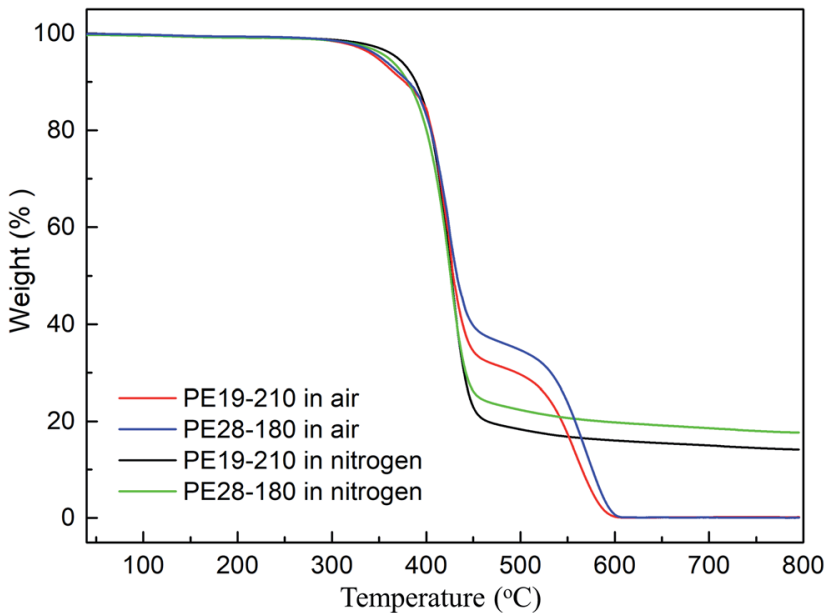

Fig. 10 The TGA curves of the cured phthalonitrile/epoxy blends in nitrogen and air atmosphere (PE19-210 and PE28-180).

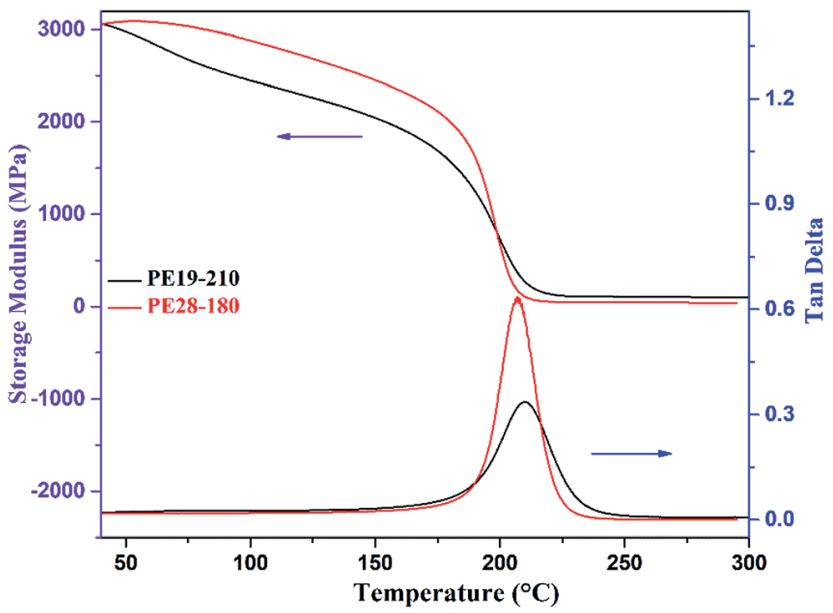

Fig. 11 The DMA curves of the cured phthalonitrile/epoxy blends (PE19-210 and PE28-180).

Table 1 The thermal and mechanical properties of PE19, PE28 and their cured products

\begin{tabular}{llllll}
\hline Sample name & $T_{5}\left({ }^{\circ} \mathrm{C}\right)$ & $T_{10}\left({ }^{\circ} \mathrm{C}\right)$ & $\mathrm{CR}(\%)$ & $T_{\mathrm{g}}\left({ }^{\circ} \mathrm{C}\right)$ & $\begin{array}{l}\text { Initial } G^{\prime} \\
(\mathrm{MPa})\end{array}$ \\
\hline PE19 & 318 & 362 & 13.6 & - & - \\
PE19-210 (N $)$ & 369 & 389 & 14.2 & - & - \\
PE19-210 (air) & 347 & 377 & 0 & 210 & 3076 \\
PE28 & 254 & 376 & 16.9 & - & - \\
PE28-180 (N $\left.\mathrm{N}_{2}\right)$ & 360 & 380 & 17.7 & - & - \\
PE28-180 (air) & 352 & 381 & 0 & 207 & 3046
\end{tabular}

PE28 exhibit good flame-retardant properties, ${ }^{25}$ which indicate that the flame-retardant properties of epoxy resin can be promoted by PNBI.

The dynamic mechanical properties of the cured PE blends were evaluated by DMA testing, and the plots of storage modulus $\left(G^{\prime}\right)$ and damping factor $(\tan \delta)$ are shown in Fig. 11. It

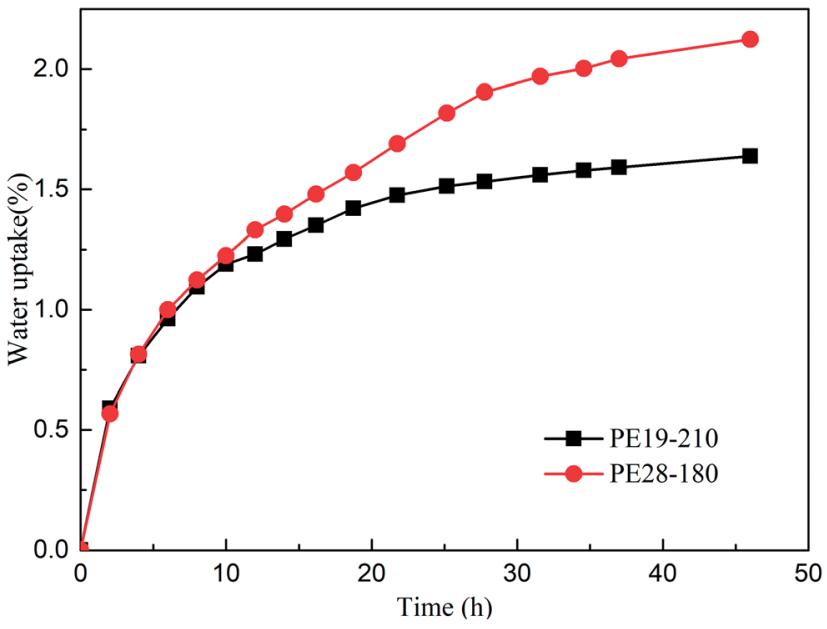

Fig. 12 Water uptake of PE19-210 and PE28-180 in boiling distilled water.

is evident from the plots that PE19-210 and PE28-180 exhibited outstanding thermal and mechanical properties. The $G^{\prime}$ of the cured PE19 and PE28 at $40{ }^{\circ} \mathrm{C}$ are up to 3076 and $3046 \mathrm{MPa}$, respectively. The $T_{\mathrm{g}}$ obtained from the peak of $\tan \delta$ of PE19-210 and PE28-180 are 210 and $207^{\circ} \mathrm{C}$, respectively, which indicates that when compared with other E51 epoxy resin systems the thermal properties of E51 could be significantly improved by the addition of PNBI. From the $G^{\prime}$ and $T_{\mathrm{g}}$ data, it could be determined that the dynamic mechanical properties of PE28-180 are lower than those of PE19-210, which may be due to a lower degree of the consumption of nitrile groups in PE28-180.

\subsection{Water uptakes}

The water uptakes of PE19-210 and PE28-180 were calculated using the following equation:

$$
\text { Water uptake }(\%)=\frac{\left(M_{2}-M_{1}\right)}{M_{1}} \times 100
$$

where $M_{1}$ and $M_{2}$ is the weight of the cured PE19 and PE28 at the dry state and after immersion in boiling distilled water, respectively.

Fig. 12 shows the water uptake properties of the cured PE blends in boiling distilled water. As shown in Fig. 12, the water uptake increases rapidly during the initial stage, and it appears to level off after approximately 48 hours in boiling distilled water. As shown in Fig. 12, the water uptake of PE28-180 (2.2\%) is higher than that of PE19-210 (1.6\%), which could be related to the water absorption of benzimidazole. The water uptake of the cured PE19 and PE28 is higher than those of other E51 resins, ${ }^{26,27}$ which could be due to water absorption nature of benzimidazole. ${ }^{28}$ Moreover, the water uptakes of the cured PE blends are lower than those of the other phthalonitrile resins. ${ }^{16,29,30}$

\section{Conclusions}

A benzimidazole-containing phthalonitrile (PNBI) was introduced to promote the curing reactions and modify the thermal 
properties of epoxy resins (E51). The results obtained show that PNBI and E51 exhibit good compatibility. The curing behaviors, structures and thermal properties of the PNBI/E51 blends (PE19 and PE28) were monitored by IR, SEM, DSC, rheology, TGA and DMA. The IR spectra of the cured PNBI/E51 blends show that nitriles would be fully consumed at a temperature lower than $150{ }^{\circ} \mathrm{C}$ in the PNBI/E51 blend system (PE19). The $T_{\mathrm{g}}$ of the cured PNBI/E51 blends were higher than $207{ }^{\circ} \mathrm{C}$, and the $T_{5}$ and CR values were higher than $360{ }^{\circ} \mathrm{C}$ and $14 \%$ in nitrogen atmosphere, respectively. This study shows a novel modification method for inhibiting the phase separation in the blend systems, preparation of phthalonitrile or epoxy systems and modification thermal properties of epoxy resins.

\section{Conflicts of interest}

There are no conflicts to declare.

\section{Acknowledgements}

The authors thank the National Natural Science Foundation of China (No. 51173114) for the financial support.

\section{Notes and references}

1 G. Yang, S. Y. Fu and J. P. Yang, Polymer, 2007, 48, 302-310. 2 J. Qin, G. Zhang, R. Sun and C. Wong, J. Therm. Anal. Calorim., 2014, 117, 831-843.

3 P. Jain, V. Choudhary and I. K. Varma, J. Macromol. Sci., Polym. Rev., 2002, 42, 139-183.

4 R. Jain, V. Choudhary and A. K. Narula, J. Appl. Polym. Sci., 2007, 106, 2593-2598.

5 D. Augustine, K. P. Vijayalakshmi, R. Sadhana, D. Mathew and C. P. R. Nair, Polymer, 2014, 55, 6006-6016.

6 Z. Gao, Y. Yu, Y. Xu and S. Li, J. Appl. Polym. Sci., 2007, 105, 1861-1868.

7 K. Zeng and G. Yang, Phthalonitrile Matrix Resins and Composites, Wiley Online Library, 2012.

8 T. M. Keller and J. R. Griffith, Resins for aerospace, ACS Symp. Ser., 1980, 25-34.

9 G. Yu, C. Liu, X. Li, J. Wang, X. Jian and C. Pan, Polym. Chem., 2012, 3, 1024-1032.
10 D. D. Dominguez and T. M. Keller, J. Appl. Polym. Sci., 2008, 110, 2504-2515.

11 X. Zhao, H. Guo, Y. Lei, R. Zhao, J. Zhong and X. Liu, J. Appl. Polym. Sci., 2013, 127, 4873-4878.

12 H. Guo, Y. Zou, Z. Chen, J. Zhang, Y. Zhan, J. Yang and X. Liu, High Perform. Polym., 2012, 24, 571-579.

13 X. Zhao, Y. Lei, R. Zhao, J. Zhong and X. Liu, J. Appl. Polym. Sci., 2012, 123, 3580-3586.

14 D. Wu, Y. Zhao, K. Zeng and G. Yang, J. Polym. Sci., Part A: Polym. Chem., 2012, 50, 4977-4982.

15 Y. Zhao, J. Zhu, X. Shen, J. Hu, K. Zeng and G. Yang, Thermosetting Resin, 2012, 27, 1-4.

16 J. Hu, Y. Liu, Y. Jiao, S. Ji, R. Sun, P. Yuan, K. Zeng, X. Pu and G. Yang, RSC Adv., 2015, 5, 16199-16206.

17 L. Liu and M. Li, J. Appl. Polym. Sci., 2010, 117, 3220-3227.

18 K. Kudo, M. Furutani and K. Arimitsu, J. Polym. Sci., Part A: Polym. Chem., 2016, 54, 3411-3414.

19 T. Vidil, F. Tournilhac, S. Musso, A. Robissonb and L. Leibler, Prog. Polym. Sci., 2016, 62, 126-179.

20 P. Yuan, S. Ji, J. Hu, X. Hu, K. Zeng and G. Yang, Polymer, 2016, 102, 266-280.

21 S. Ji, P. Yuan, J. Hu, R. Sun, K. Zeng and G. Yang, Polymer, 2016, 84, 365-370.

22 F. Zhao, R. Liu, X. Yu, K. Naito, X. Qu and Q. Zhang, J. Appl. Polym. Sci., 2015, 132, 42606.

23 Y. Huang, Y. Luo, M. Xu, Y. Lei and X. Liu, Composites, Part B, 2016, 106, 294-299.

24 D. W. van Krevelen, Polymer, 1975, 16, 615-620.

25 C. H. Lin and C. S. Wang, Polymer, 2001, 42, 1869-1878.

26 P. Ren, G. Liang and Z. Zhang, Polym. Compos., 2006, 27, 591-598.

27 S. G. Prolongoa, G. del Rosariob and A. Urena, Int. J. Adhes. Adhes., 2006, 26, 125-132.

28 J. Hu, P. Yuan, K. Zeng and G. Yang, Thermochim. Acta, 2014, 590, 30-39.

29 S. B. Sastri and T. M. Keller, J. Polym. Sci., Part A: Polym. Chem., 1999, 37, 2105-2111.

30 H. Sheng, X. Peng, H. Guo, X. Yu, C. Tang, X. Qu and Q. Zhang, Mater. Chem. Phys., 2013, 142, 740-747. 